\title{
A ATA NOTARIAL COMO MEIO DE PROVA EM CASOS DE CYBERBULLYING
}

\author{
Mariana Moreira Neves* \\ Cinthia Obladen de Almendra Freitas**
}

SUMÁRIO: Introdução; 2 Conceituação de Bullying e suas Consequências; 30 Bullying e seus Desdobramentos no Ordenamento Jurídico Brasileiro; 4 O Sistema Probatório no Direito Processual Civil Brasileiro; 5 AAta Notarial como Mecanismo de Provas Digitais; 6 Conclusão; Referências.

RESUMO: O presente artigo trata dos casos de cyberbullying, que por mais que o nome sugira ser apenas o bullying realizado por meio eletrônico, demonstra-se ser ainda mais grave. Estuda-se o bullying de modo a compreender o cyberbullying, suas características e desdobramentos no ambiente escolar. Demonstra-se a importância da Ata Notarial como mecanismo de prova no combate ao cyberbullying e como prova considerando o sistema legal, a conscientização e mobilização quanto aos direitos e garantias que tutelam a igualdade entre todos, não havendo razão para manter, muito menos fomentar, a violação da dignidade das vítimas, por meio digital. Para isso, analisa-se a Constituição Federal, o Estatuto da Criança e do Adolescente, o Código Civil e o Código de Defesa do Consumidor.

PALAVRAS-CHAVE: Consumidor; Cyberbullying; Direito e Tecnologia; Meio de prova; Novas Tecnologias.

\section{NOTARY MINUTES AS PROOF IN CYBERBULLYING CASES}

ABSTRACT: Current analysis deals with cases of cyberbullying which, in spite of the term which qualifies it as mere bullying through electronic means, is more serious than that. Bullying is investigated to understand cyberbullying, and its characteristics and development within the school environment. The importance of the Notary Minutes as proof against cyberbullying and as a legal proof is underscored, coupled to conscience-raising and mobilization with regard to rights and guarantees that tutelage equality. Therefore, there is no rightful argument to maintain, or worse, to incentive, the violation of the victim's dignity by digital means. The Brazilian

\footnotetext{
Advogada. Mestre em Direito Econômico e Socioambiental pela Pontifícia Universidade Católica do Paraná (PUCPR), Curitiba (PR), Brasil; E-mail: marianamoreiraneves@gmail.com

** Docente Titular da Pontifícia Universidade Católica (PUCPR); Docente Permanente dos Programas de Pós-Graduação em Direito (PPGD) e em Informática (PPGIa) Pontifícia Universidade Católica (PUCPR); Doutora em Informática pela Pontifícia Universidade Católica (PUCPR), Curitiba (PR), Brasil..
} 
Federal Constitution, the Statute for Children and Adolescents, Civil Code and the Consumers' Code are investigated on the theme.

KEY WORDS: Consumer; Cyberbullying; Law and Technology; Proofs; New Technologies.

\section{LA ACTA NOTARIAL COMO MEDIO DE PRUEBA EN CASOS DE CYBERBULLYING}

RESUMEN: El presente artículo trata de los casos de cyberbullying, que por más que el nombre sugiera ser solo el bullying realizado por medio electrónico, demuestra ser mucho más grave. Se estudia el bullying de modo a comprender el cyberbullying, sus características y desdoblamientos en el entorno escolar. Se demuestra la importancia de la Acta Notarial como mecanismo de prueba en el combate al cyberbullying y como prueba considerando el sistema legal, la concienciación y movilización frente a los derechos y garantías que tutelan la igualdad entre todos, no habiendo razón para mantener, mucho menos fomentar, la violación de la dignidad de las víctimas, por medio digital. Para ello, se analiza la Constitución Federal, El Estatuto del Niño y del Adolescente, el Código Civil y el Código de Defensa del Consumidor.

PALABRAS-CLAVE: Consumidor, Cyberbullying; Derecho y Tecnología, Medio de Prueba; Nuevas Tecnologías.

\section{INTRODUÇÃO}

O bullying pode parecer simples, mas não é. A Safernet ${ }^{3}$, em 2013, recebeu e processou 9.807 denúncias anônimas de Intolerância Religiosa, 15.141 de Homofobia e 78.690 de Racismo, sendo a rede social Facebook a mais denunciada ${ }^{4}$. Outro ponto relevante foi apresentado no Relatório "TIC Crianças 2010"5 do Centro de Estudos sobre as Tecnologias da Informação e da Comunicação (Cetic.

\footnotetext{
3 A Safernet é uma associação civil de direito privado, com atuação nacional, sem fins lucrativos ou econômicos, sem vinculação político partidária, religiosa ou racial. Fundada em 20 de dezembro de 2005 por um grupo de cientistas da computação, professores, pesquisadores e bacharéis em Direito, a organização surgiu para materializar ações concebidas ao longo de 2004 e 2005, quando os fundadores desenvolveram pesquisas e projetos sociais voltados para o combate à pornografia infantil na Internet brasileira. Disponível em: $<$ http:// www.safernet.org.br/site/institucional> Acesso em: 06 jun. 2014.

${ }_{4}^{4}$ Disponível em: < http://indicadores.safernet.org.br/> Acesso em: 06 jun. 2014.

${ }^{5}$ CETIC.br - Centro de Estudos sobre as Tecnologias da Informação e da Comunicação. Pesquisa sobre o uso de tecnologias de informação e comunicação no Brasil: TIC Crianças 2010. Coordenação executiva e editorial: Alexandre F. Barbosa. São Paulo: Comitê Gestor da Internet no Brasil, 2012, p. 10.
} 
br) mostrando que $21 \%$ das crianças, entre cinco a nove anos de idade de todo o território brasileiro, acessam sozinhas a rede mundial de computadores, sem nenhuma supervisão ou controle parental. E esta situação não foi diferente em 2012, quando o Relatório "TIC Kids Online Brasil 2012" apontou que "Em casa, o uso das tecnologias pelas crianças nem sempre ocorre com a supervisão dos pais, familiares ou pessoas mais velhas e, mesmo quando há supervisão, em virtude do desconhecimento das potencialidades dessas tecnologias, os adultos nem sempre têm a compreensão de seus perigos". O Relatório aponta que 38\% das crianças, da classe $A B$, utilizam a Internet em seus próprios quartos e que $6 \%$ responderam que "alguém já tinha feito brincadeiras ou piadas com elas pela Internet que elas não tinham gostado".

Muitos são os questionamentos relacionados a este tema, tal qual Freitas e Villatore ${ }^{7}$, os quais estudaram o bullying no ambiente de trabalho e perguntam que tipo de prova pode ser formalizado para demonstrar a conduta, reiterada ou não, do agressor. Preocupavam-se os autores com os elementos caracterizadores deste tipo de problema.

Considerando-se o exposto, o artigo busca analisar o cyberbullying, as características que o diferenciam do bullying, sua repercussão no meio digital e as consequências que pode acarretar à vítima, tratando em especial o ambiente escolar. Além disto, analisa-se o sistema probatório do direito processual civil brasileiro e, por fim, estuda-se a Ata Notarial como meio de prova em processos judiciais que envolvam o cyberbullying.

Demonstra-se que, apesar do Brasil não haver redigido Lei Federal específica sobre o assunto, a dignidade, a moral, a integridade, entre outros direitos fundamentais das vítimas encontram-se tuteladas pela Constituição Federal, pelo Estatuto da Criança e do Adolescente (ECA), e que é possível responsabilizar o agressor por meio de dispositivos do Código Civil e também do Código de Defesa do Consumidor (CDC). Trata-se, ainda, dos meios de provas aceitos pelo ordenamento jurídico brasileiro, breve análise jurisprudencial quanto às provas oriundas de meios eletrônicos e, então, apresenta-se a Ata Notarial como uma solução para auxiliar a questão probatória nos casos de cyberbullying.

\section{CONCEITUAÇÃO DE BULLYING E SUAS CONSEQUÊNCIAS}

\footnotetext{
${ }^{6}$ CETIC.br - Centro de Estudos sobre as Tecnologias da Informação e da Comunicação. TIC Kids Online Brasil 2012 [livro eletrônico]: pesquisa sobre o uso da Internet por crianças e adolescentes. Coord. executiva e editorial: Alexandre F. Barbosa. São Paulo: Comitê Gestor da Internet no Brasil, 2013, p. 83 e 134.

7 FREITAS, Cinthia Obladen de Almendra. et al. Assédio moral em mensagens eletrônicas no ambiente de trabalho: identificação e emoções associadas. Disponível em: <http://www.ppgia.pucpr.br/ paraiso/mineracaodeemocoes/recursos/118160.pdf > . Acesso em: 14 maio 2014.
} 
O bullying começou a ser estudado na década de 1970 por Dan Olweus, pesquisador de origem suíça na Universidade de Bergen, na Noruega ${ }^{8}$. No Brasil, este fenômeno deixou de ser considerado uma brincadeira de criança e passou a ser abordado pelos aspectos psicossociais, científicos e jurídicos, a partir do ano de $2000^{9}$.

Proveniente da língua inglesa, a expressão bullying caracteriza o uso de violência física e/ou psicológica, intencional e reiterada ao longo do tempo, praticada por um indivíduo ou por um grupo, para intimidar ou agredir pessoas mais frágeis ou impossibilitadas de se defender, caracterizando uma relação de superioridade/ inferioridade ${ }^{10}$.

Existem outros termos para caracterizar este tipo de agressão. Na Noruega, Suécia, Dinamarca e Finlândia a expressão utilizada é mobbing. A raiz inglesa " $m o b$ " refere-se a um grupo grande e anônimo de pessoas que se dedicam ao assédio. Mesmo sendo praticado por um ou mais indivíduo, a palavra que se emprega a estes comportamentos é a mesma, por mais estranho que possa parecer do ponto de vista linguístico ${ }^{11}$.

Na França diz-se barcèlement quotidien; na Itália, prepotenza ou bullismo; no Japão, yjimer; na Alemanha agressionen unter shulern; na Espanha, acoso y amenaza entre escolares; em Portugal, como maus-tratos entre pares ${ }^{12}$.

Os agressores, conhecidos também por bullies - termo que em inglês significa valentão ${ }^{13}$ - possuem habilidades sociais restritas, normalmente geradas por uma supervisão parental pobre, de estilo comportamental autoritário ${ }^{14}$. Estes costumam atingir crianças e adolescentes frágeis, solitários, introvertidos e de autoestima baixa.

Observa-se que as vítimas de bullying - pessoas que sofrem as agressões e se sentem lesionadas por estas - normalmente possuem características físicas ou

\footnotetext{
${ }_{8}^{8}$ OLWEUS Bullying Prevention Program. Disponível em: <http://www.clemson.edu/olweus/history.html $>$. Acesso em: 06 jun. 2014.

9 SILVA, Ana Beatriz Barbosa. Mentes perigosas nas escolas: bullying. Rio de Janeiro: Objetiva, 2010a, p. 161.

${ }^{10}$ TRINDADE, Jorge. Manual de Psicologia Jurídica para operadores do Direito. Porto Alegre: Livraria do Advogado, 2009 , p. 376.

${ }^{11}$ FANTE, Cleo. Fenômeno Bullying: Como prevenir a violência nas escolas e educar para a paz. Campinas: Versus, 2012, p. 27.

${ }^{12}$ Ibidem, 2012, p. 28.

${ }^{13}$ Wordreference.com Online language Dictionaries. Disponível em: < http://www.wordreference.com $>$. Acesso em: 06 jun. 2014.

${ }^{14}$ BRAGA, Lélio Calhau. Bullying: o que você precisa saber: identificação, prevenção e repressão. Niterói: Impetus, 2011, p. 51.
} 
psicológicas que as diferenciam dos demais, como por exemplo: obesidade, uso de óculos, aparelho dentário, modo de falar, vestir ou se comportar, necessidades especiais, classe social diferenciada, credo, raça ou orientação sexual diferente, inteligência superior ou inferior aos demais, entre outros. A criatividade do agressor se vê atraída por tais características e a partir disto começam a surgir as ofensas.

Entre as ofensas físicas e psicológicas, as mais comuns são as verbais (insultar, ofender, falar mal, colocar apelidos pejorativos, fazer piadas ofensivas), as físicas (bater, empurrar, beliscar, furtar ou destruir pertences da vítima, atirar-lhe objetos) e as psicológicas (humilhar, excluir, isolar, discriminar, ameaçar, perseguir) e as sexuais (abusar, violentar e assediar sexualmente).

Por outro lado, acredita-se também na hipótese de que tais afrontas físicas e/ou psicológicas podem resultar de características psíquicas do próprio agressor, simplesmente por reconhecer uma relação de superioridade, independente de qual seja, entre ele e a vítima. É o entendimento da psiquiatra e professora Ana Beatriz Barbosa Silva:

É fundamental explicitar que as atitudes tomadas por um ou mais agressores contra um ou alguns estudantes, geralmente, não apresentam motivações específicas ou justificáveis. Isso significa dizer que, de forma quase 'natural', os mais fortes utilizam os mais frágeis como meros objetos de diversão, prazer e poder, com o intuito de maltratar, intimidar, humilhar e amedrontar suas vítimas. E isso, invariavelmente, sempre produz, alimenta e até perpetua muita dor e sofrimento nos vitimados ${ }^{15}$.

Não raras vezes, os bullies se utilizam de sua autoridade para dominar a maioria do grupo e impedir que os outros se solidarizem quanto ao ofendido, acarretando maior isolamento e sofrimento.

Aqueles que se encontram em desvantagem quanto ao agressor e aos demais espectadores, podem vir a carregar sequelas físicas e mentais para toda a vida. Na maior parte dos casos o primeiro sintoma é a diminuição do rendimento acadêmico e a tendência a não gostar do ambiente escolar, não tendo motivação para comparecer às aulas ${ }^{16}$.

O Conselho Nacional de Justiça preocupou-se com o tema e discorreu na "Cartilha 2010 - Justiça nas Escolas" sobre as consequências do Bullying, a saber:

\footnotetext{
${ }^{15}$ SILVA, Ana Beatriz Barbosa. 2010a, p. 21.

${ }^{16}$ GOULART, Nathalia. É responsabilidade da escola combater o bullying. Veja. 10 abr. 2011. Disponível em: $<$ http://veja.abril.com.br/noticia/educacao/e-responsabilidade-da-escola-combater-o-bullying $>$. Acesso em: 06 jun. 2014.
} 
As consequências são as mais variadas possíveis e dependem muito de cada indivíduo, da sua estrutura, de vivências, de predisposição genética, da forma e da intensidade das agressões. No entanto, todas as vítimas, sem exceção, sofrem com os ataques de bullying (em maior ou menor proporção). Muitas levarão marcas profundas provenientes das agressões para a vida adulta, e necessitarão de apoio psiquiátrico e/ou psicológico para a superação do problema. Os problemas mais comuns são: desinteresse pela escola; problemas psicossomáticos; problemas comportamentais e psíquicos, como transtorno do pânico, depressão, anorexia e bulimia, fobia escolar, fobia social, ansiedade generalizada, entre outros. O bullying também pode agravar problemas preexistentes, devido ao tempo prolongado de estresse que a vítima é submetida. Em casos mais graves, podem-se observar quadros de esquizofrenia, homicídio e suicídio ${ }^{17}$.

Todos estes sintomas podem aparecer de modo ainda mais acentuado quando as agressões se perpetuam através de meios eletrônicos, caracterizando assim o cyberbullying. Esta modalidade acontece por meio de telefonemas, câmeras, mensagens de texto de celular (SMS), além de muitos outros que se utilizam da Internet, como é o caso de e-mails, redes sociais, sites, blogs, fotologs, entre outros.

Quanto aos elementos caracterizadores, assim como no bullying, é preciso haver, por parte do agressor, intenção de machucar, humilhar, desmoralizar, causar danos à vítima e, também, a vítima precisa se sentir de algum modo lesionada.

Entretanto, quando se fala sobre a conduta do agressor ocorrer de modo reiterado, existem opiniões divergentes. Para Shariff ${ }^{18}$, Hinduja e Patchin ${ }^{19}$, considerase cyberbullying quando o comportamento hostil apresenta-se de forma repetitiva. Em contrapartida, Ana Maria de Albuquerque $\operatorname{Lima}^{20}$ constrói outro pensamento. Para a autora, "um aspecto a ser levado em conta é a quantidade de vezes que um determinado vídeo ou site de cyberbullying é visualizado por terceiros na Internet".

Um só ato de bullying que fora gravado, filmado, fotografado, ao ser

\footnotetext{
${ }^{17}$ SILVA, Ana Beatriz Barbosa. Bullying. Cartilha 2010: Justiça nas Escolas. CNJ. Brasília, 2010b, p. 9. Disponível em: <http:/download.rj.gov.br/documentos/10112/157756/DLFE-59223.pdf/cartilha_webbullying.pdf>. Acesso em: 06 jun. 2014.

${ }^{18}$ SHARIFF, Shaheen. Cyberbullying: issues and solutions for the school, the classroom and the home. Nova York: Rotledge, 2008, p. 29.

${ }^{19}$ HINDUJA, Sameer; PATCHIN, Justin. Bullying beyond the schoolyard. Prevention and responding to cyberbullying. Thousand Oaks: Corwin Press, 2009, p. 5.

${ }^{20}$ LIMA, Ana Maria de Albuquerque. Cyberbullying e outros riscos na Internet: despertando a atenção de pais e professores. Rio de Janeiro: Wak, 2011, p. 75.
} 
postado na Internet, ou mesmo enviado por e-mail, pode ser visualizado por um número absolutamente maior de pessoas, se comparado com as pessoas que presenciaram o fato.

Cada um que obtiver acesso a este conteúdo poderá repassá-lo e assisti-lo quantas vezes quiser. Por mais que esta possa parecer uma informação irrelevante para os espectadores, é algo que acentua de modo imensurável o sofrimento da vítima. Perde-se o controle do alcance do que foi veiculado, visto que a Internet é fator multiplicador, no que tange aos acessos de dados e informações.

Outro fator que agrava esta situação é o anonimato. Por meio da Internet os agressores se sentem protegidos por poderem se esconder, se passar por outra pessoa ou até mesmo fingir que é a própria vítima. Aquele que não teria coragem de realizar um ato violento contra a vítima pessoalmente, no mundo físico, por detrás do computador, no mundo digital, pode cometer lesões irreparáveis.

Maria Tereza Maldonado ainda argumenta que esta sensação de anonimato que a Internet proporciona faz com que os autores cometam agressões muito mais pesadas do que as que ousariam realizar pessoalmente. Fator que possibilita a extinção do requisito da relação de desigualdade, vez que no espaço cibernético o "menino franzino" é capaz de se tornar o "valentão" e perturbar a vítima mesmo sem precisar presenciar seu sofrimento, como explicado

[...] no cyberbullying, pode acontecer que o agressor nunca esteja no mesmo espaço físico que sua vítima e consiga permanecer anônimo por muito tempo, atacando em momentos inesperados, por vezes de madrugada, sobressaltando a vítima que está dormindo. A própria casa ou o quarto aconchegante deixam de ser um lugar seguro. A impressão é de um atentado terrorista: a face do inimigo está oculta, não se sabe quem é, e nem quando ou de onde partirá o ataque seguinte ${ }^{21}$.

O Relatório "Guidelines for Preventing cyber-bullying in the School Environment: a review and recommendations" (2013, p. 5), organizado pelo Grupo de Trabalho 3 do $\operatorname{COST}^{22}$ Action IS0801, aponta que o envolvimento positivo dos pais e responsáveis está associado com menos casos de bullying entre os adolescentes.

\footnotetext{
${ }^{21}$ MALDONADO, Maria Tereza. Bullying e Cyberbullying: o que fazemos com o que fazem conosco? São Paulo: Moderna, 2011, p. 63.

${ }^{22}$ COST is an intergovernmental framework for European Cooperation in Science and Technology, allowing the coordination of nationally-funded research on a European level. COST contributes to reducing the fragmentation in European research investments and opening the European Research Area to cooperation worldwide. Disponível em: < http://www.cost.eu/about_cost> Acesso em: 06 jun. 2014.
} 
Indica ainda que uma supervisão deficiente e falta de atenção em casa, aceitação por parte dos pais de comportamento agressivo, disciplina severa e modelo paterno de comportamento agressivo estão associados com o bullying. Outro ponto relevante é o fato de que os bullies que utilizam a Internet e os celulares possuem pais menos envolvidos com os conhecimentos das novas tecnologias e o uso da Internet por parte de seus filhos ${ }^{23}$.

No ambiente escolar, por exemplo, as ofensas têm começo, meio e fim. Contudo, quando estas ocorrem por meio da Internet, as vítimas são perseguidas como um fantasma que chega sem previsão para ir embora, causando muito sofrimento também para familiares e pessoas próximas. Cabe, portanto, avaliar como o bullying é enfrentado no ordenamento jurídico brasileiro.

\section{O BULLYING E SEUS DESDOBRAMENTOS NO ORDENAMENTO JURÍDICO BRASILEIRO}

No Brasil, apesar de não existir ainda uma legislação federal que ampare ou tipifique a prática de bullying - físico ou cibernético - os pilares da proteção jurídica às vítimas se configuram, primeiramente por meio da Constituição Federal, bem como do Estatuto da Criança e do Adolescente (ECA) ${ }^{24}$, do Código Civil ${ }^{25}$ e do Código de Defesa do Consumidor (CDC) ${ }^{26}$.

A Carta Maior traz em seu art. $1^{\circ}$, os princípios fundamentais e entre eles está a dignidade da pessoa humana, no seu inc. III. Alexandre Morais explica do que trata este princípio:

A dignidade da pessoa humana atribui unidade aos direitos e garantias fundamentais, inerente às personalidades humanas afastando a ideia de predomínio das concepções transpessoalistas de Estado e Nação, em função da liberdade individual. A dignidade é um valor espiritual e moral intrínseco da pes-

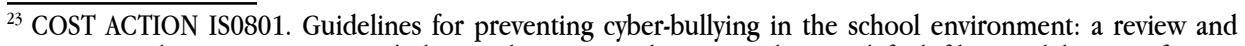
recommendations. 2013. Disponível em: < https://www.bee-secure.lu/sites/default/files/Guidelines\%20for\%20 preventing\%20cyber-bullying_COSTIS_0801.pdf $>$ Acesso em: 06 jun. 2014.

${ }^{24}$ BRASIL. Lei 8.069 de 13 de julho de 1990 . Estatuto da Criança e do Adolescente. Disponível em: < http://www. planalto.gov.br/ccivil_03/leis/18069.htm> Acesso em: 06 jun. 2014.

${ }^{25}$ BRASIL. Lei 10.406 de 10 de janeiro de 2002. Código Civil. Disponível em: < http://www.planalto.gov.br/ ccivil_03/leis/2002/110406.htm> Acesso em: 06 jun. 2014.

${ }^{26}$ BRASIL. Lei 8.078 de 11 de setembro de 1990. Código de Defesa do Consumidor. Disponível em: < http:// www.planalto.gov.br/ccivil_03/leis/8078.htm > Acesso em: 06 jun. 2014. 
soa, que se manifesta singularmente na sua autodeterminação consciente e responsável, trazendo consigo a pretensão ao respeito das demais pessoas, edificando um mínimo invulnerável que todo estatuto jurídico deve assegurar, de modo que, excepcionalmente, possam ser feitas limitações ao exercício dos direitos fundamentais, todavia sem menosprezar o merecimento das pessoas enquanto seres humanos ${ }^{27}$.

Luís Roberto Barroso justifica a importância da dignidade da pessoa humana ser tratada como um princípio:

A identificação da dignidade humana como um princípio jurídico produz consequências relevantes no que diz respeito à determinação de seu conteúdo e estrutura normativa, seu modo de aplicação e seu papel no sistema constitucional. Princípios são normas jurídicas com certa carga axiológica, que consagram valores ou indicam fins a serem realizados, sem explicitar comportamentos específicos. Sua aplicação poderá se dar por subsunção, mediante ponderação, em caso de colisão com outras normas de igual hierarquia. Além disso, seu papel no sistema jurídico difere do das regras, na medida em que eles se irradiam por outras normas, condicionando seu sentido e alcance ${ }^{28}$.

Ademais, o art. 227 do texto constitucional dispõe que:

É dever da família, da sociedade e do Estado assegurar à criança, ao adolescente e ao jovem, com absoluta prioridade, o direito à vida, à saúde, à alimentação, à educação, ao lazer, à profissionalização, à cultura, à dignidade, ao respeito, à liberdade e à convivência familiar e comunitária, além de colocá-los a salvo de toda forma de negligência, discriminação, exploração, violência, crueldade e opressão ${ }^{29}$.

Ou seja, é direito da criança ter sua dignidade, integridade e liberdade respeitadas, bem como ter acesso à educação, à cultura e para isto, é necessário que ela compareça às atividades, sem medo de que na escola seja tratada de maneira desigual, inferiorizada, desconsiderando sua condição humana.

Neste sentido, tem-se também a Lei 8.069/90, o Estatuto da Criança e

\footnotetext{
${ }^{27}$ MORAIS, Alexandre de. Direito Constitucional. 17. ed. São Paulo: Atlas, 2005, p.16.

${ }^{28}$ BARROSO, Luís Roberto. A Dignidade da pessoa humana no direito constitucional contemporâneo: natureza jurídica, conteúdos mínimos e critérios de aplicação. Versão provisória para debate público. Mimeografado, 2010, p. 12.

${ }^{29}$ BRASIL. Constituição da República Federativa do Brasil de 05 de outubro de 1988. Disponível em: < http:// www.planalto.gov.br/ccivil_03/constituicao/constituicao.htm >. Acesso em: 06 jun. 2014.
} 
do Adolescente (ECA), o qual zela pelos direitos fundamentais das crianças e dos adolescentes, pelo desenvolvimento físico, mental, moral, espiritual e social, em condições de liberdade e dignidade, pela primazia de receber proteção e socorro em quaisquer circunstâncias, entre outros.

Ainda, o art. $5^{\circ}$ da Constituição Federal, que trata de direitos e garantias fundamentais, em seu inciso X estabelece que "são invioláveis a intimidade, a vida privada, a honra e a imagem das pessoas, assegurando o direito à indenização pelo dano material ou moral decorrente de sua violação" ${ }^{30}$.

Ao discriminar uma criança por alguma característica física e/ou psicológica, agredi-la verbal ou fisicamente, vasculhar e destruir seus pertences, isolá-la, fazê-la passar por situações vexatórias, diminuir sua condição humana, entre outras animosidades características do bullying, fica evidente que a dignidade, a integridade, a intimidade, a honra e a imagem das vítimas são desrespeitadas.

Neste diapasão, o art. 186 do Código Civil trata dos atos ilícitos, "aquele que, por ação ou omissão voluntária, negligência ou imprudência, violar direito e causar dano a outrem, ainda que exclusivamente moral, comete ato ilícito" ${ }^{31}$. Por sua vez, garante o art. 927 do Código Civil que "aquele que, por ato ilícito (arts. 186 e 187), causar dano a outrem fica obrigado a repará-lo"32.

Então, presume-se, após conhecimento da legislação pátria, que o agressor ou seus responsáveis, no caso de um menor cometer o ilícito gerador da lesão, poderão ser responsabilizados pelos seus atos, devendo indenizar à vítima pelos danos que sofrera.

José Fernando Simão explica que no caso de responsabilidade pelo ato dos filhos, em regra, pai e mãe respondem civil e objetivamente pela indenização. Com relação a ser o pai ou a mãe quem deve indenizar, o autor esclarece que entre eles a responsabilidade é solidária. Pode a vítima cobrar integralmente o valor da indenização do pai ou da mãe, aquele que resolver a obrigação tem direito de regresso quanto ao co-responsável ${ }^{33}$.

Nos casos de bullying escolar, o estabelecimento de ensino também é responsável pela reparação civil dos danos causados aos seus alunos, consoante o inciso IV do art. 932 do Código Civil: "São também responsáveis pela reparação

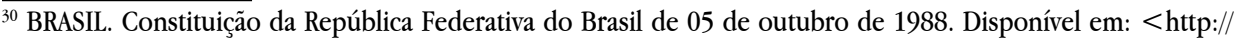
www.planalto.gov.br/ccivil_03/constituicao/constituicao.htm > . Acesso em: 06 jun. 2014.

${ }^{31}$ BRASIL. Lei 10.406 de 10 de janeiro de 2002. Código Civil. Disponível em: < http://www.planalto.gov.br/ ccivil_03/leis/2002/10406.htm >. Acesso em: 06 jun. 2014.

${ }^{32}$ BRASIL. Lei 10.406 de 10 de janeiro de 2002. Código Civil. Disponível em: <http://www.planalto.gov.br/ ccivil_03/leis/2002/10406.htm >. Acesso em: 06 jun. 2014.

${ }^{33}$ SIMÃ̄O, José Fernando. Responsabilidade civil do incapaz. São Paulo: Atlas, 2008, p. 140-145.
} 
civil: os donos de hotéis, hospedarias, casa ou estabelecimentos onde se albergue por dinheiro, mesmo para fins de educação, pelos seus hóspedes, moradores e educandos" ${ }^{34}$.

Por mais que não seja a escola em si que pratique o bullying, entendese que ela pode preveni-lo ou evitá-lo. Contudo, independentemente de culpa, o art. 933 do Código Civil estabelece seu dever de reparação: "As pessoas indicadas nos incisos I a V do artigo antecedente, ainda que não haja culpa de sua parte, responderão pelos atos praticados pelos terceiros ali referidos" 35 .

Identifica-se que o instituto da responsabilidade civil é abordado no Código Civil e também no Código de Defesa do Consumidor (CDC) ${ }^{36}$. O art. 14 do CDC dispõe que "o fornecedor de serviços responde, independente da existência de culpa, ou seja, de forma objetiva, pela reparação dos danos causados aos consumidores por defeitos relativos à prestação dos serviços".

Antônio Carlos Efing entende que a responsabilidade pode derivar por fato do serviço, repercussão danosa extrínseca às características dos defeitos juridicamente relevantes, por exemplo, quando determinado serviço não oferece a segurança que os consumidores poderiam esperar ou por vício do serviço, quando a finalidade não é atingida ${ }^{37}$.

Diante de um conflito de leis no tempo/espaço, há a solução de uma lei nova revogar a lei mais antiga, ou da lei específica revogar a lei geral, ou até mesmo o critério hierárquico. Esta pluralidade de leis é o primeiro desafio do aplicador da lei contemporâneo, portanto faz-se necessário estudar o diálogo das fontes. Cláudia Lima Marques ensina que é possível estabelecer um diálogo entre estas legislações, na tentativa de encontrar a equivalência necessária à sua aplicação no caso concreto ${ }^{38}$.

O CDC é considerado um microssistema das relações de consumo e equiparadas, de caráter preventivo e coletivo. Já o Código Civil é um macrossistema das relações privadas, de caráter preventivo apenas sob determinados aspectos e individual. Portanto, o Código Civil não exclui a aplicação do $\mathrm{CDC}$, todavia é

\footnotetext{
$\overline{{ }^{34} \text { BRASIL. Lei } 10.406}$ de 10 de janeiro de 2002. Código Civil. Disponível em: <http://www.planalto.gov.br/ ccivil_03/leis/2002/10406.htm>. Acesso em: 06 jun. 2014.

${ }^{35}$ BRASIL. Lei 10.406 de 10 de janeiro de 2002. Código Civil. Disponível em: <http://www.planalto.gov.br/ ccivil_03/leis/2002/110406.htm>. Acesso em: 06 jun. 2014.

${ }^{36}$ BRASIL. Lei 8.078 de 11 de setembro de 1990. Código de Defesa do Consumidor. Disponível em: < http:// www.planalto.gov.br/ccivil_03/leis/8078.htm> Acesso em: 06 jun. 2014.

${ }^{37}$ EFING, Antônio Carlos. Fundamentos do direito das relações de consumo. 3. ed. Curitiba: Juruá, 2011, p. 44.

${ }^{38}$ MARQUES, Cláudia Lima. Contratos no Código de Defesa do Consumidor. 5. ed. São Paulo: Revista dos Tribunais, 2005, p. 664.
} 
complementar ou acessório nas matérias em que guarda competência.

É a lição de Cláudia Lima Marques: "Útil, pois, é a ideia de 'diálogo' das fontes, diálogo que significa a aplicação simultânea, coordenada e sistemática destas duas leis principais e coexistentes de Direito Privado brasileiro" ${ }^{39}$. Neste mesmo diapasão, esclarece Antônio Carlos Efing que:

O diálogo sistemático e coerência busca a aplicação simultânea de duas leis a mesma situação concreta, sendo um diploma fundamento conceitual ao outro. Observa-se, no entanto, a aplicação complementar de uma lei em relação à outra no diálogo sistemático de complementaridade em antinomias aparentes ou reais, que visa o alcance tanto de normas quanto dos princípios de forma subsidiária ou complementar de uma lei em relação à outra, quando ambas têm o mesmo campo de incidência. Já o diálogo de coordenação e adaptação sistemática ou das influências recíprocas sistemáticas prima pela possibilidade de mudança no campo de aplicabilidade legal através da análise dos conceitos e sujeitos definidos nos diplomas legais ${ }^{40}$.

Em face à pluralidade, percebe-se que o direito não é visto mais como algo estático, mas sim como um conjunto de leis que se inter-relacionam, em busca da solução mais justa para determinados casos concretos.

Atualmente, parte da doutrina acredita que os pressupostos tradicionais da responsabilidade civil já não suprem mais as necessidades sociais, uma vez que o dever de indenizar varia no tempo e no espaço, de acordo com fenômenos econômicos, sociais e culturais que interferem em cada sistema jurídico.

Roberto Altheim esclarece o assunto com o seguinte exemplo: "Um dano que hoje é indenizável por determinada pessoa no Brasil pode não sê-lo em outro país ou em outro tempo" ${ }^{41}$. Neste sentido, adotam-se, então, novos pressupostos para a responsabilização civil, os quais não têm como finalidade proporcionar uma sanção àquele que praticou conduta contrária ao Direito, mas reparar de maneira integral a vítima que sofrera o dano injusto.

Utilizando-se deste raciocínio, pode-se entender que em casos de bullying escolar, a instituição de ensino poderá ser responsabilizada não por ser o agente praticante da conduta ilícita, mas por não oferecer a segurança esperada pelo serviço que presta, ou ainda, por não ter adotado medidas suficientes para resolver

\footnotetext{
${ }^{99}$ Id., Superação das antinomias pelo diálogo das fontes: o modelo brasileiro de coexistência entre o Código de Defesa do Consumidor e o Código Civil de 2002. Revista de Direito do Consumidor, n. 51. São Paulo: Revista dos Tribunais, 2003, p. 67.

${ }^{40}$ EFING, op. cit., 2011, p. 44.

${ }^{41}$ ALTHEIM, Roberto. Direito de danos: pressupostos contemporâneos do dever de indenizar. Curitiba: Juruá, 2012, p. 14.
} 
o conflito. A escola responderá pelo fato de ser a parte envolvida que melhor e mais rapidamente, por motivos econômicos, irá proporcionar a restituição do status quo ante à vítima lesionada, atenuando o sofrimento causado pelo bullying.

Nos casos de bullying e, principalmente cyberbullying, é aconselhável agir rápido e com segurança, no que tange à proteção das provas, não somente para se conseguir descobrir a identidade do agressor, mas também para pleitear em juízo pela responsabilização, seja do agente, dos pais (no caso de agente incapaz) e/ou da escola, buscando a reparação do injusto dano sofrido.

\section{O SISTEMA PROBATÓRIO NO DIREITO PROCESSUAL CIVIL BRASILEIRO}

A definição jurídica de prova, consoante Luiz Guilherme Marinoni e Sérgio Cruz Arenhart, é "todo o meio retórico, regulado pela lei, dirigido a, dentro dos parâmetros fixados pelo direito e de critérios racionais, convencer o Estado-juiz da validade das proposições, objeto de impugnação, feitas no processo" ${ }^{\prime 2}$.

Para Pontes de Miranda, "a prova no processo é o que concorre para que o juiz, ao aplicar a lei, fique certo de que está a prestar, com exatidão, o que se prometera: a tutela jurídica” ${ }^{\prime 3}$.

O Código de Processo Civil, em seu art. 332, dispõe que todos os meios de prova são hábeis para demonstrar a veracidade dos fatos em que se funda a demanda, empregando o vocábulo prova para significar os meios de prova, como a prova testemunhal, documental, pericial, ou qualquer outro meio de prova possível, ainda que não esteja previsto em lei.

Serão admitidos como objeto de prova processual apenas aqueles que demonstrarem relevância quanto à comprovação dos fatos alegados na defesa. Conforme os arts. 302 e 334 do referido Código, não necessitam de comprovação nos Autos, os fatos admitidos pela outra parte, ou ainda os não negados, os de notório saber e sob os quais milita a seu favor presunção legal de existência ou de veracidade.

Santiago Sentís Melendo entende que a finalidade da prova não é comprovar

\footnotetext{
${ }^{42}$ MARINONI, Luiz Guilherme; ARENHART, Sérgio Cruz. Manual do processo de conhecimento. São Paulo: Revista dos Tribunais, 2006, p. 267.

${ }^{43}$ MIRANDA, Francisco Cavalcanti Pontes de. Comentários ao Código de Processo Civil. Rio de Janeiro: Forense, 1996, p. 246.
} 
o fato que existe ou existiu. $O$ que se pretende com a prova é demonstrar que as afirmações de defesa referem-se àqueles fatos, é a comprovação das afirmações ${ }^{44}$.

De acordo com o princípio do livre convencimento, o juizé livre para formar sua convicção acerca da apreciação dos elementos de prova. Ovídio Baptista da Silva, ao referir-se a este princípio, explica que "o juiz poderá formar o seu convencimento não apenas baseado naquilo que a testemunha afirmou, mas igualmente fundado em suas impressões pessoais colhidas tanto no comportamento da própria testemunha, quanto nas atitudes e comportamento processual das partes” ${ }^{45}$.

Assim, entende-se que a prova carreada ao processo por algum meio de prova, servirá para comprovar as afirmações de defesa que cada parte trouxer, para auxiliar no processo de conhecimento do juiz, não sendo obrigado este a se vincular a estas provas.

Quanto aos casos de bullying, sabe-se que todos os meios lícitos de provas são admitidos e, como visto anteriormente, é fácil vislumbrar os tipos de provas que um caso destes apresentaria, por exemplo, prova testemunhal e documental.

Entretanto, quando se fala de cyberbullying este pensamento se torna um pouco mais complexo. O que fazer para comprovar informações postadas na Internet, mensagens de celular, fotos, vídeos, troca de mensagens eletrônicas, entre outros?

É o entendimento de Lélio Calhau Braga:

Um dos problemas no cyberbullying é a demora de sua apuração. Embora com a tecnologia atual, através do IP, seja possível identificar a conexão que originou a possível agressão, a demora na apuração desses crimes ainda é um complicador. [...] Em casos de ocorrência de cyberbullying, imprima imediatamente a página da Internet, após copiá-la através da tecla print screen. Faça isso na primeira página da comunidade da rede social (por exemplo) e comunidade de Orkut (se for esse o caso) e onde estiverem presentes as supostas ofensas contra a honra da vítima. É extremamente importante que você imprima e guarde esses materiais (copie em um CD ou pendrive, por segurança $)^{46}$.

O desembargador Helimar Pinto, do Tribunal de Justiça do Estado

\footnotetext{
${ }^{44}$ MELENDO, Santiago Sentís. La prueba: los grandes temas del derecho probatorio. Buenos Aires: EJEA, 1979, p. 409.

${ }^{45}$ SILVA, Ovídio A. Baptista da; GOMES, Fábio Luiz. Teoria geral do processo civil. São Paulo: Revista dos Tribunais, 2011, p. 274.

${ }^{46}$ BRAGA, op. cit., 2011, p. 69.
} 
do Espírito Santo, quando da decisão da Apelação Cível no 12090033742, em 13 de março de 2012, na qual uma jovem teve problemas em comprovar que havia denunciado ao Google a criação de perfil falso em seu nome, com exposição de fotos íntimas, pronunciou-se da seguinte maneira, acerca de prova de documento da Internet: "a única prova eficiente no caso é a documental e tal prova é extremamente simples de ser produzida, bastando a impressão da mensagem de recebimento da denúncia no próprio site ou cópia da notificação extrajudicial” ${ }^{77}$.

No mesmo sentido, de apenas imprimir documento oriundo da Internet, entendeu o desembargador José Anchieta da Mota e Silva, do Tribunal de Justiça do Estado de Minas Gerais, é a ementa:

Agravo Interno. Juntada de cópia da guia de recolhimento do preparo e impressão do recibo de pagamento efetuado via Internet. Mera irregularidade. Agravo conhecido e provido. Estando o TJMG vivenciando um momento histórico de implantação do processo virtual, é inconcebível não aceitar como prova de pagamento do preparo recursal a impressão do recibo de pagamento efetuado via Internet ${ }^{48}$.

Percebe-se que alguns operadores do Direito aceitam a possibilidade de a mera impressão de algo que esteja disponível na Internet constituir prova para processo judicial. Contudo, pode-se pensar que o papel é um instrumento onde se aceita tudo. Qualquer tipo de informação pode ser colocado no papel, falsa ou verdadeira. Então, como se proteger e/ou se garantir que a demonstração de coisa realizada em casos de cyberbullying seja autêntica?

\section{A ATA NOTARIAL COMO MECANISMO DE PROVAS DIGITAIS}

Documentos digitais, gravados na memória principal de computadores ou em memórias secundárias (HD, pen-drive, CD, DVD, entre outros), ou ainda resultantes de cálculos efetuados por meio de equipamentos eletrônicos, uma vez impressos e nada mais, comprometem os procedimentos de aferição, por não haver possibilidade de se saber com exatidão, sua origem, autoria, o dia e hora que

\footnotetext{
${ }^{47}$ BRASIL. Tribunal de Justiça do Espírito Santo. $1^{\text {a }}$ Câmara Cível. Rel. Des. Helimar Pinto. Apelação Cível no 12090033742 , j.13.03.2012.

${ }^{48}$ BRASIL. Tribunal de Justiça do Estado de Minas Gerais. 15a Câmara. Rel. Des. José Anchieta da Mota e Silva. Agravo Interno $\mathrm{n}^{\mathrm{0}} 1.0080 .05 .000685-9 / 002(1)$, j. 10.01.2008.
} 
esteve disponível na rede, entre outros detalhes. Sobre este assunto discorre Luiz Guilherme Marinoni e Sérgio Cruz Arenhart:

No que atine à comunicação de dados por via de rede informatizada de comunicação (Internet), a questão se agrava, na medida em que a transmissão da informação poderá ser feita por qualquer pessoa, podendo ainda haver a interferência de terceiros no curso da comunicação. Não se tem, por outro lado, segurança quanto à origem do documento, à idoneidade do transmissor ou mesmo quanto ao local e tempo em que ocorreu o envio da informação. Pensa-se em alguma forma de assinatura eletrônica, capaz de conferir alguma autenticidade aos dados. Todavia, o tema ainda está em fase totalmente incipiente para permitir alguma segurança jurídica (especialmente em relação à matéria de provas) ${ }^{49}$.

Nota-se que os autores, em 2006, não imaginavam que os mecanismos de autenticidade no mundo digital fossem evoluir tão rapidamente.

Pontua-se, portanto, que não se pode obter segurança jurídica de que impressões diretas de sites, e-mails, entre outros, guardam alguma conformidade com a realidade, visto que não se pode emprestar-lhes plausibilidade. Como uma solução a estes problemas, tem-se a Ata Notarial. Seu conceito encontra-se no item 11.10.1 do Código de Normas da Corregedoria Geral de Justiça do Paraná:

Ata notarial é a certificação de fatos jurídicos, a requerimento da parte interessada e por constatação pessoal do tabelião, substituto ou escrevente, cujo objeto não comporte a lavratura de escritura pública. Pode ser lavrada ata notarial, entre outros exemplos, para a captura de imagens e de conteúdos de sites da Internet, vistorias em objetos e lugares, bem como narração de situações fáticas, com intuito de prevenir direitos e responsabilidades $^{50}$.

Em outras palavras, a Ata Notarial é um instrumento utilizado como meio de prova, requerido por um particular ao notário (agente público), para que o mesmo autentique fatos, como, por exemplo, os provenientes da Internet, para que tal documento produzido pelo notário, uma vez gozando de fé pública, possa constituir meio de prova confiável ao processo judicial, possibilitando ao Juiz formar seu convencimento acerca dos argumentos contidos na defesa. Assim, o "princípio

\footnotetext{
${ }^{49}$ MARINONI; ARENHART, op. cit., 2006, p. 351-352.

${ }^{50}$ BRASIL. Provimento $\mathrm{n}^{\mathrm{O}} 59$ do Código de Normas da Corregedoria Geral do Paraná. Disponível em: < http:// www.tj.pr.gov.br/cgj/download/pr/pr059.pdf> . Acesso em: 06 jun. 2014.
} 
geral é que o tabelião pode relatar tudo aquilo que seus sentidos lhe transmitem de forma inequívoca, inclusive som e imagem" 51 .

O notário irá descrever o que for apresentado pela parte, de maneira fidedigna, sem em nenhum momento emitir juízo de valor àquilo que se está diante, caso o contrário, poderá responder civil e penalmente pela sua declaração ${ }^{52}$.

Irá constar na Ata Notarial o nome e qualificação do solicitante, conteúdo, local, dia e horário, declaração de leitura da ata pelo solicitante, assinatura do solicitante e testemunhas, sinal público do tabelião, entre outros elementos que existam e possam auxiliar o processo de conhecimento ${ }^{53}$.

Os serviços notariais e de registro são exercidos em caráter privado, por delegação do Poder Público, conforme o art. 236 da Constituição Federal da República. Ainda, o inc. III, do artigo $7^{\circ}$, da Lei n. 8935/1994 dispõe que o tabelião é exclusivamente competente para produzir a Ata Notarial.

Desta forma, percebe-se que a Ata Notarial é um documento público através do disposto no art. 364 do Código de Processo Civil: "O documento público faz prova não só da sua formação, mas também dos fatos que o escrivão, o tabelião ou o funcionário declarar que ocorreram em sua presença". Portanto, a Ata Notarial tem a mesma força probatória que uma certidão extraída por um tabelião, conforme o art. 217 do Código Civil.

Quanto ao caráter de documento público, têm-se o ensinamento de Luiz Guilherme Marinoni e Sérgio Cruz Arenhart:

Será público quando o seu autor imediato seja agente investido de alguma função pública, e quando a formação do documento se dê no exercício desta função; trata-se normalmente, de alguma função documentadora ou certificadora, regulada pelo próprio Estado. Note-se que, nesse caso, a ideia continua sendo do particular; mas por ter sido presenciada a declaração por algum servidor público, no exercício de função estatal típica (mas não obrigatoriamente documentadora), o documento terá diversa eficácia probatória ${ }^{54}$.

Os autores ainda esclarecem que "essa diversidade de valor probante

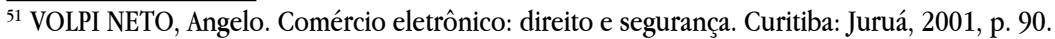

${ }^{52}$ FERREIRA, Paulo Roberto Gaiger; RODRIGUES, Felipe Leonardo. Ata notarial, doutrina, prática e meio de prova. São Paulo: Quartier Latin, 2010, p. 152.

53 VOLPI NETO, Angelo. Ata notarial de documentos eletrônicos. Disponível em: < http://www.notariado.org. $\mathrm{br} /$ index.php?pG $=X 19 \mathrm{leGliZV9ub3RpY2lhcw}==\& \mathrm{in}=\mathrm{MzM1NQ}==\&$ filtro $=9 \&$ Data $>$ Acesso em: 06 jun. 2014.

${ }^{54}$ MARINONI; ARENHART, op. cit., 2006, p. 349.
} 
não resulta, diretamente, de alguma certificação especial dos fatos declarados pelo particular perante o ofício público, mas sim da certeza quanto à autoria dessas declarações"

Para Ângelo Volpi Neto, a Ata Notarial serve como uma prevenção. Como a Internet possibilita que a informação nela compartilhada seja rapidamente colocada e com a mesma agilidade retirada da rede, é aconselhável a produção da Ata Notarial para que no momento processual adequado de produção de provas, se consiga demonstrar que aquele conteúdo referido nos Autos esteve disponível em ambiente digital e público em determinada época. Não é porque o documento não mais existe que ele nunca existiu e não causou danos a alguém ${ }^{56}$.

Destaca-se que ao se solicitar uma Ata Notarial, o tabelião ou escrevente solicitará ao interessado que acesse com login (nome do usuário) e senha, de propriedade do interessado, o local (site, perfil em rede social, caixa de entrada de e-mails, sala de bate-papo (chats), entre outros. Desta forma, configura-se que o interessado recebeu o conteúdo de caráter assedioso.

Não se poderá provar a autoria e a origem do conteúdo recebido, se este não estiver assinado digitalmente. $\mathrm{E}$, como na prática, quem assedia não assina, somente por meio de solicitação judicial ao provedor do serviço ou perícia é que se poderão levantar todos os indícios que levarão à autoria do referido conteúdo.

Percebe-se que a Ata Notarial é um mecanismo que proporciona maior segurança jurídica à vítima, sua família e ao Juiz para formação de seu convencimento acerca dos fatos narrados no processo judicial. É a melhor forma de "eternizar" aquilo que fora escrito, postado ou mostrado de modo online, já que a Internet é um meio volátil de publicação e retirada de informações.

\section{CONCLUSÃO}

Com este estudo percebe-se que o bullying não se trata de uma brincadeira de criança, ao contrário, pode causar consequências graves, tanto físicas como psicológicas. O assunto se agrava quando a violência se realiza por meios eletrônicos, devido à facilidade que a tecnologia proporciona de mascarar a identidade do agente

\footnotetext{
${ }_{55}$ MARINONI; ARENHART, op. cit., 2006.

${ }^{56}$ VOLPI NETO, Angelo. Ata notarial de documentos eletrônicos. Disponível em: <http://www.notariado.org. $\mathrm{br} /$ index.php?pG $=X 191 \mathrm{eGliZV9ub3RpY2lhcw}==\& \mathrm{in}=\mathrm{MzM} 1 \mathrm{NQ}==\&$ filtro $=9 \&$ Data $>$. Acesso em: 06 jun. 2014 .
} 
que comete o ilícito e ademais pela facilidade de postagem, circulação e extinção daquilo que fora publicado no meio digital.

Por mais que não haja uma Lei Federal sobre o problema em questão, o mesmo não se faz imprescindível dado que a Constituição Federal e o Estatuto da Criança e do Adolescente zelam pelos direitos fundamentais inerentes à pessoa humana. Ainda, o Código Civil e o Código de Defesa do Consumidor tratam sobre a responsabilização do agente, dos pais do agressor quando este incapaz e/ou da instituição de ensino, de modo a realizar a reparação da vítima por meio de indenização.

Ainda, demonstra-se que o sistema probatório brasileiro admite a prova documental, testemunhal, pericial e todos os outros meios que a parte consiga trazer a lide de modo lícito. A prova deverá ser feita sobre os fatos controvertidos e relevantes para o processo, de modo a auxiliar a formação do convencimento do Juiz, não o vinculando a nenhum resultado, vez que provam os argumentos utilizados e não reconstroem os fatos.

Vislumbra-se por meio de decisões jurídicas que os fatos provenientes de meios eletrônicos podem ser simplesmente impressos e carreados ao processo judicial. Admite-se também a comprovação dos mesmos pela formalização de Ata Notarial.

Por ser um instrumento realizado por agente público, dotado de fé pública, o qual responde civil e penalmente por suas declarações, a Ata Notarial mostra-se como o melhor meio de prova para demonstrar atos de cyberbullying vez que proporciona segurança jurídica.

Por ser a Internet um meio de comunicação volátil, os agressores podem postar e retirar informações de acordo com sua vontade e interesse, o que dificulta a comprovação da existência da violência pela vítima no caso de um processo judicial.

Não é porque se retirou da rede que a agressão não existiu, não repercutiu, não causou danos a alguém. A Ata Notarial apresenta-se, portanto, como uma solução segura e eficaz, tanto para a prevenção da vítima, como para fins de comprovação dos fatos perante o Poder Judiciário.

Finalmente, reforça-se a atitude preventiva dos pais e responsáveis e, também, da escola, visto que o Relatório "Guidelines for Preventing cyber-bullying in the School Environment: a review and recommendations" reconhece que é importante que os pais tenham competência para formar e educar as crianças e os 
adolescentes para o uso de tecnologias. Além disto, aponta que a tecnologia deve ser utilizada para interagir positivamente com outros. Assim, cabe aos pais/responsáveis e à escola, orientar, ajudar e capacitar as crianças nas relações sociais, considerando que tais jovens irão se relacionar em diferentes contextos sociais, inclusive o digital. Desta forma, acredita-se que não se pode somente ofertar a tecnologia, mas demonstrar que existem riscos e responsabilidades. Somente assim haverá uma evolução para o binômio prevenção-proteção.

\section{REFERÊNCIAS}

ALTHEIM, Roberto. Direito de danos: pressupostos contemporâneos do dever de indenizar. Curitiba: Juruá, 2012.

BARROSO, Luís Roberto. A dignidade da pessoa humana no direito constitucional contemporâneo: natureza jurídica, conteúdos mínimos e critérios de aplicação. Versão provisória para debate público. Mimeografado, 2010.

BRAGA, Lélio Calhau. Bullying: o que você precisa saber: identificação, prevenção e repressão. Niterói: Impetus, 2011.

BRASIL. Constituição da República Federativa do Brasil de 05 de outubro de 1988. Disponível em: <http://www.planalto.gov.br/ccivil_03/constituicao/ constitui\%C3\%A7ao.htm > . Acesso em: 06 jun. 2014.

BRASIL. Lei 10.406 de 10 de janeiro de 2002. Código Civil. Disponível em: < http:// www.planalto.gov.br/ccivil_03/leis/2002/110406.htm > . Acesso em: 06 jun. 2014.

BRASIL. Lei 8.069 de 13 de julho de 1990. Estatuto da Criança e do Adolescente. Disponível em: < http://www.planalto.gov.br/ccivil_03/leis/18069.htm > Acesso em: 06 jun. 2014.

BRASIL. Lei 8.078 de 11 de setembro de 1990. Código de Defesa do Consumidor. Disponível em: < http://www.planalto.gov.br/ccivil_03/leis/18078.htm> Acesso em: 06 jun. 2014.

BRASIL. Provimento ${ }^{0} 59$ do Código de Normas da Corregedoria Geral do Paraná. Disponível em: < http://www.tj.pr.gov.br/cgj/download/pr/pr059.pdf> . Acesso em: 06 jun. 2014. 
BRASIL. Tribunal de Justiça do Espírito Santo. $1^{\text {a }}$ Câmara Cível. Rel. Des. Helimar Pinto. Apelação Cível no 12090033742 , j.13.03.2012.

BRASIL. Tribunal de Justiça do Estado de Minas Gerais. 15a Câmara. Rel. Des. José Anchieta da Mota e Silva. Agravo Interno $\mathrm{n}^{0}$ 1.0080.05.000685-9/002(1), j. 10.01.2008.

COST ACTION IS0801. Guidelines for preventing cyber-bullying in the school environment: a review and recommendations. 2013. Disponível em: < https:// www.bee-secure.lu/sites/default/files/Guidelines\%20for\%20preventing\%20cyber -bullying_COSTIS_0801.pdf> Acesso em: 06 jun. 2014.

EFING, Antônio Carlos. Fundamentos do direito das relações de consumo. 3. ed. Curitiba: Juruá, 2011.

FANTE, Cleo. Fenômeno Bullying: como prevenir a violência nas escolas e educar para a paz. Campinas: Versus, 2012.

FERREIRA, Paulo Roberto Gaiger; RODRIGUES, Felipe Leonardo. Ata notarial, doutrina, prática e meio de prova. São Paulo: Quartier Latin, 2010.

FREITAS, Cinthia Obladen de Almendra et al. Assédio moral em mensagens eletrônicas no ambiente de trabalho: identificação e emoções associadas. Disponível em: < http://www.ppgia.pucpr.br/ paraiso/mineracaodeemocoes/recursos/118160. pdf $>$. Acesso em: 14 maio 2014.

GOULART, Nathalia. É responsabilidade da escola combater o bullying. Veja. $10 \mathrm{abr}$. 2011. Disponível em: <http://veja.abril.com.br/noticia/educacao/e-responsabilidade-da-escola-combater-o-bullying > . Acesso em: 06 jun. 2014.

HINDUJA, Sameer; PATCHIN, Justin. Bullying beyond the schoolyard: prevention and responding to cyberbullying. Thousand Oaks: Corwin Press, 2009.

LIMA, Ana Maria de Albuquerque. Cyberbullying e outros riscos na Internet: despertando a atenção de pais e professores. Rio de Janeiro: Wak, 2011.

MALDONADO, Maria Tereza. Bullying e Cyberbullying: o que fazemos com o que fazem conosco? São Paulo: Moderna, 2011.

MARINONI, Luiz Guilherme; ARENHART, Sérgio Cruz. Manual do processo de conhecimento. São Paulo: Revista dos Tribunais, 2006.

MARQUES, Cláudia Lima. Contratos no Código de Defesa do Consumidor. 5. ed. 
São Paulo: Revista dos Tribunais, 2005.

MELENDO, Santiago Sentís. La prueba: los grandes temas del derecho probatório. Buenos Aires: EJEA, 1979.

MIRANDA, Francisco Cavalcanti Pontes de. Comentários ao Código de Processo Civil. Rio de Janeiro: Forense, 1996.

MORAIS, Alexandre. Direito Constitucional. 17. ed. São Paulo: Atlas, 2005.

OLWEUS Bullying Prevention Program. Disponível em: < http://www.clemson.edu/ olweus/history.html> . Acesso em: 06 jun. 2014.

SHARIFF, Shaheen. Cyberbullying: issues and solutions for the school, the classroom and the home. Nova York: Rotledge, 2008.

SILVA, Ana Beatriz Barbosa. Mentes perigosas nas escolas: Bullying. Rio de Janeiro: Objetiva, 2010a, p. 161.

SILVA, Ana Beatriz Barbosa. Bullying: Cartilha 2010 - Justiça nas Escolas. CNJ. Brasília, 2010b, p. 9. Disponível em: <http://download.rj.gov.br/documentos/10112/157756/DLFE-59223.pdf/cartilha_webbullying.pdf > . Acesso em: 06 jun. 2014.

SILVA, Ovídio A. Baptista da; GOMES, Fábio Luiz. Teoria Geral do Processo Civil. São Paulo: Revista dos Tribunais, 2011.

SIMÃO, José Fernando. Responsabilidade civil do incapaz. São Paulo: Atlas, 2008. TRINDADE, Jorge. Manual de psicologia jurídica para operadores do Direito. Porto Alegre: Livraria do Advogado, 2009.

VOLPI NETO, Angelo. Ata notarial de documentos eletrônicos. Disponível em: $\quad<$ http://www.notariado.org.br/index.php?pG =X19leGliZV9ub3RpY2lhc$\mathrm{w}==\& \mathrm{in}=\mathrm{MzM} 1 \mathrm{NQ}==\&$ filtro $=9 \&$ Data $>$ Acesso em: 06 jun. 2014.

VOLPI NETO, Angelo. Comércio eletrônico: direito e segurança. Curitiba: Juruá, 2001.

WORDREFERENCE.com Online language Dictionaries. Disponível em: <http:// www.wordreference.com > . Acesso em: 06 jun. 2014. 
Recebido em: 03 de fevereiro de 2015

Aceito em: 30 de março de 2015 